\title{
La enfermera victoriana: género e imperio
}

\section{A enfermeira vitoriana: gênero e império The Victorian Nurse: gender and empire}

\author{
Francisco-Javier Castro-Molina \\ Doctor enfermero de salud mental. Historiador del Arte. Antropólogo. \\ Complejo Hospitalario Universitario de Canarias. Servicio Canario de Salud. \\ Cómo citar este artículo en edición digital: Castro-Molina, F.J. (2016). La enfermera victoriana: género e imperio. \\ Cultura de los Cuidados (Edición digital), 20( 46). \\ Disponible en: < http://dx.doi.org/10.14198/cuid.2016.46.09> \\ Correspondencia: Calle Las Trebinas 24-San Miguel de Geneto-San Cristóbal de La Laguna. \\ 38296-Santa Cruz de Tenerife. \\ Correo Electrónico: tenerifejavier@gmail.com \\ Recibido: 03/08/2015; Aceptado: 20/08/2016
}

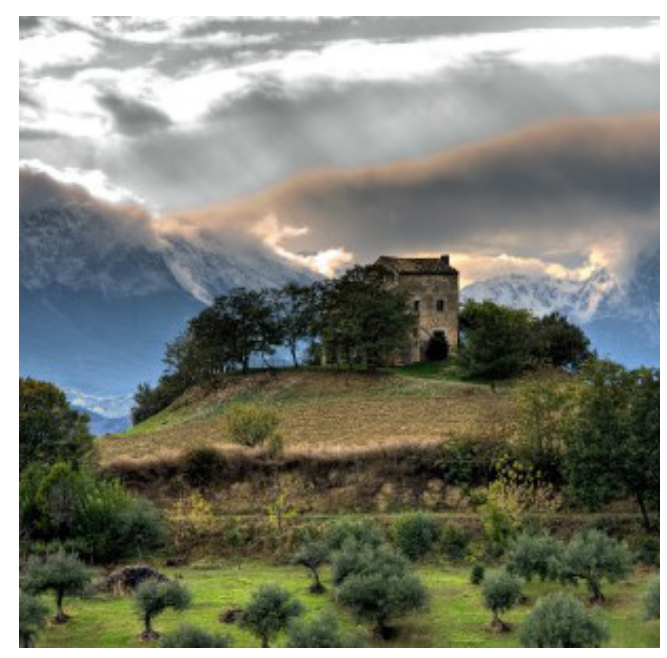

\section{ABSTRACT}

The emancipatory critique that characterized the Enlightenment was the tool that facilitated the presence of ideas such as equality, autonomy and solidarity. This broth was behind the emergence of a feminist movement that criticized the androcentric society that characterized the Victorian Era. The claims of the women focused on the right to vote and access to education that go beyond the elementary, ie the university. Major social changes that emerged from the Industrial Revolution, women joined the workforce. The struggle for equal was the catalyst for the emergence of the union, which sought to eliminate body models like the andropolítico that was established in England.

The feminist ideology polluted every one of the structures that made up the various British authorities. Nursing, a discipline that until then had not consolidated as a profession was influenced by this movement. Florence Nightingale left clearly defined its position in the different publications that made the midnineteenth century. They define the role of the nurse and their relation to the figure of the doctor. In addition, Nightingale established a eulogy speech for equality with men, emphasizing the importance of training women.

Key words: Nightingale, nurse, Victorian Era, gender, education, union.

\section{RESUMO}

A crítica emancipatória que caracterizou o Iluminismo foi a ferramenta que facilitou a presença de idéias como a igualdade, autonomia e solidariedade. Este caldo estava por trás do surgimento de um movimento feminista que criticava a sociedade androcêntrica que caracterizou a Era Vitoriana . As reivindicações das mulheres focada no direito de votar e de acesso à educação que vão além do básico 
, ou seja, a universidade. Grandes mudanças sociais que surgiram a partir da Revolução Industrial, as mulheres se juntou à força de trabalho. A luta pela igualdade foi o catalisador para o surgimento do sindicato, que procurou eliminar modelos de corpo como o andropolítico que foi estabelecida na Inglaterra.

A ideologia feminista poluída a cada uma das estruturas que compõem as várias autoridades britânicas. Enfermagem, uma disciplina que até então não havia consolidado como uma profissão foi influenciado por este movimento. Florence Nightingale deixou claramente definida a sua posição nas diferentes publicações que fizeram a meados do século XIX . Eles definem o papel do enfermeiro e sua relação com a figura do médico. Além disso, Nightingale estabeleceu um discurso panegírico de igualdade com os homens, enfatizando a importância da formação das mulheres .

Palavras-chave: Nightingale, enfermeira, Era Vitoriana, gênero, educação, união.

\section{RESUMEN}

La crítica emancipadora que caracterizó a la Ilustración fue la herramienta que facilitó la presencia de ideas tales como igualdad, autonomía y solidaridad. Este caldo de cultivo fue el que favoreció la aparición de un movimiento feminista que criticó a la sociedad androcéntrica que caracterizó a la Época Victoriana. Las reivindicaciones de las mujeres se centraron en el derecho al voto y un acceso a la educación que fuera más allá de la elemental, es decir, la universitaria. Los importantes cambios sociales que surgieron a raíz de la Revolución Industrial, incorporaron a la mujer al mundo laboral. La lucha por la igualdad de condiciones fue el detonante del surgimiento del sindicato, órgano que procuraba eliminar modelos como el andropolítico que estaba ar- raigado en Inglaterra.

El ideario feminista contaminó todas $y$ cada una de las estructuras que conformaban las diferentes colectividades británica. La Enfermería, disciplina que hasta ese momento no se había consolidado como profesión, se vio influenciado por este movimiento. Florence Nightingale dejó claramente definida su postura en las diferentes publicaciones que realizó a mediados del siglo XIX. En ellas define el rol de la enfermera y su relación con la figura del médico. Además, Nightingale establece un discurso panegírico por la igualdad con el hombre, enfatizando en la importancia que tiene la formación en la mujer.

Palabras clave: Nightingale, enfermera, Época Victoriana, género, educación, sindicato.

\section{INTRODUCCIÓN}

El movimiento feminista que surge en el seno de la sociedad victoriana fue el motor de reivindicaciones que buscaban un mayor protagonismo público del papel de la mujer. La educación superior y la capacidad de decisión en la elección del poder ejecutivo estuvieron presentes en un discurso que en ocasiones atacaba directamente a los contrarios en género. Pero esta ansiada búsqueda de la igualdad también se preocupó por la vertiente laboral, campo al que paulatinamente se fueron incorporando las mujeres.

Las féminas y sus necesidades proyectaron su ansia de cambio hacia todos los colectivos de la sociedad británica. Gestionada por mujeres desde siglos atrás, la disciplina de los cuidados, protoprofesión en ese momento, también fue influida por esta corriente del pensamiento. Florence Nightingale no solo confecciona el primer programa oficial de entrenamiento de enfermeras que materializó en su Escuela 
Nightingale en 1860, sino que además, en sus textos, estableció tanto su postura con respecto a la figura de la mujer en el ámbito sanitario como la definición del rol social de las «dispensadoras de cuidados».

Con el presente documento se pretende concretar, analizar e interpretar el ideario feminista desde una vertiente sociohistóricoantropológica que la «heroína de Crimea» dejó inserto en el discurso presente tanto en las Notas de Enfermería como en Sugerencias para pensar para legisladores de las verdades religiosas.

\section{MATERIAL Y MÉTODO}

El presente documento constituye una revisión bibliográfica que aglutina tres ópticas diferentes: la social, la sanitaria, la antropológica y la histórica. Para ejecutarla se han empleado tanto recursos bibliográficos en soporte papel (libros y tesis doctorales) como recursos electrónico que abordan disciplinas como la Historia y las Ciencias de la Salud alojados en fuentes como CUIDEN, SCIELO y PubMed.

\section{RESULTADOS-DISCUSIÓN-CONCLU- SIÓN}

Numerosos autores han procurado dar una definición fiel al concepto de feminismo. La labor no ha sido nada sencilla. Celia Amorós lo define como toda lucha desarrollada con la finalidad de lograr la igualdad de género, articulado a partir de un eje de vindicaciones de las mujeres que piden un reconocimiento para sí (Amorós, 2008). Nancy Cott procura ir más allá. Para ella, este movimiento social es una creencia que se enfoca hacia la igualdad del género, anulando concepciones previas que durante mucho tiempo lo han jerarquizado de manera férrea (Cott, 1987). Pese a que parece una lucha de las generaciones más cercanas, esto no es así. Contra unas concepciones que por derecho divino el hombre había impuesto a sus opuestas en género, muchas han sido las féminas que paulatinamente han ido manifestando su desacuerdo. La Ilustración es el punto de partida para la teoría crítica emancipadora que supone este movimiento, articulado a partir de tres pilares: igualdad, autonomía y solidaridad. El feminismo constituye un movimiento transformador, que centra su actividad en enjuiciar las relaciones de poder a nivel de género, fundamentando su estrategia en un ataque continuo a la sociedad androcéntrica. Concepción Arenal es un claro ejemplo de esta contienda sexista. Como activista fue la instaladora del feminismo en España, procurando erradicar el ideario machista de la rancia sociedad española. Destacó por revelarse desde muy joven contra la tradicional marginación del sexo femenino, reivindicando la igualdad de las mujeres en todas las esferas sociales (Salas Iglesias, 2012).

Este movimiento de masas se conceptúa estructuradamente mediante un proceso diferenciado en etapas, a las que algunos autores han denominado «olas». El ocaso del periodo decimonónico fue uno de estos primeros momentos. La figura femenina comenzó a estar presente, casi de manera permanente, en un entorno que le había sido vetado hasta ese instante. El difícil mundo de la política, le abrió sus puertas mediante una activa participación en campañas de captación de adeptos desarrolladas en los periodos electorales. La nueva actividad favoreció un importante coqueteo con los movimientos socio-reformistas, capitaneados por el Cartismo. Esta corriente del pensamiento surgió en el Reino Unido, con la mera finalidad de expresar la agitación de la clase obrera, motivada por la Revolución Industrial, la coyuntura económica y la legislación vigen- 
te que en ese momento era promulgada por el Parlamento inglés. Además, solicitaban el derecho al voto de los hombres mayores cuerdos $\mathrm{y}$ sin antecedentes penales, la confidencialidad del voto y la participación de los obreros en el Parlamento mediante la abolición del requisito de propiedad para asistir al mismo (Jones, 1989).

\section{Imagen 1}

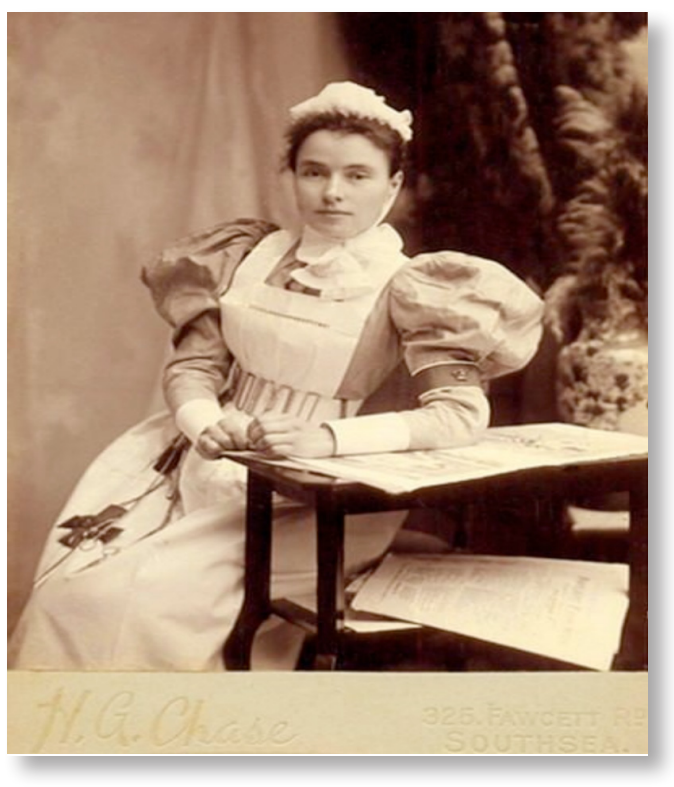

Enfermera de época victoriana (mediados siglo XIX).

Los primeros pasos del feminismo anglosajón vinieron marcados por Mary Wollstonecraft. Con su obra publicada en 1792, Vindicación de los Derechos de la Mujer, criticó la situación de ésta en la sociedad británica, señalando la conexión existente entre el sistema político anglosajón y las relaciones de poder entre los sexos. Estas formas de autoridad eran sobre todo sustentadas por modelos de gobierno tales como el absolutismo, en los que se consideraba al hombre como un único tirano que ejercía su poder en el ámbito de la familia y la casa. Además, estableció como clave para la emancipación, el acceso a la educación, herramienta necesaria para producir un plano de igualdad con respecto al hombre, logrando así la independencia económica precisa para acceder a la actividad laboral justamente remunerada (Wollstonecraft, 2012). A Wollstonecraft se le unió John Stuart Mill, uno de los más destacados pensadores liberales británicos, quien centró su discurso en la consecución del derecho de voto para la mujer. Establecía que la solución estaba en la eliminación de toda traba legislativa discriminatoria, lo que suponía una superación del «sometimiento» y el alcance de la soberanía. Junto a su mujer, Harriet Taylor Mill, publicó El Sometimiento de la Mujer en 1869. De enorme impacto, fue publicado en Estados Unidos, Australia, Nueva Zelanda, Francia, Alemania, Austria, Suecia y Dinamarca, convirtiéndose en un elemento clave de la expansión e internacionalización del movimiento sufragista. En él se proponía un establecimiento de la libertad individual basada en el principio de «liderazgo laissez faire», modelo que lograba la desaparición de impedimentos legales, conquistando un desarrollo de la personalidad de las mujeres y el pleno ejercicio de sus capacidades (Mill, 2005). En 1866, Mill presentó en el Parlamento inglés la solicitud de la legalización del voto femenino. El unánime rechazo a esta posibilidad provocó que un año después se creara el National Society for Woman's Suffrage, liderada por Lydia Becker. Esta última creía que las mujeres llevaban mucho tiempo siendo "propiedad de los hombres» y que el fin de esta situación vendría marcado con el reconocimiento del derecho al voto. Becker logró su objetivo de manera parcial con un descontento generalizado, ya que solo consiguió que votasen las mujeres solteras, olvidando a todas aquellas mujeres casadas. 
A estos planteamientos se les unió un marcado interés por la defensa del estatus laboral, el cual se convirtió en el caballo de batalla del movimiento feminista anglosajón. El esplendor del mandato de la Reina Victoria y su gobierno, estaba caracterizado por un dominio de casi la cuarta parte de la población mundial. Esta situación provocó que Gran Bretaña se viera sumida en un periodo de profundos cambios sociales. El surgimiento de la revolucionaria industria trajo aparejado un considerable aumento de la población trabajadora que procedía de zonas rurales. Buscaban una oportunidad, inexistente en los lugares de procedencia, que la veían materializada en las grandes fábricas. Pese a que las empresas ofrecían trabajo, las condiciones laborales eran deplorables: sueldos muy bajos y lugares de trabajo peligrosos donde eran habituales los accidentes y la muerte. El trabajo infantil era común, y suponía un 25 por ciento de la población laboral activa. En 1844 se prohibió que la jornada laboral de los niños de 9 a 13 años fuera superior a 6,5 horas al día, y las mujeres y los jóvenes de entre 13 y 18 años, no más de 12 horas por jornada (Howsbawm, 2009).

La lucha por la igualdad empleó como herramienta el sindicato, que se creó específicamente para ello. Su objetivo se centraba en la defensa de la mujer como ente trabajador y miembro de la sociedad civil. Dentro del movimiento destacaron básicamente dos líderes: Josephine Butler y Sarah Emily Davis. La primera ha sido considerada una de las primeras feministas inglesas, que desde temprana edad fue agente activo de campañas que buscaban promover el acceso de las mujeres de estratos sociales desfavorecidos a la educación. Junto a ello, realizó una espléndida labor social que se centró en prestar cuidados y atención médicas a prostitutas, a las que consideraba como una forma de explotación masculina, denunciando activamente la doble moral de la sociedad victoriana por su acción de premio-castigo hacia la actividad de las «mujeres de mala vida» (Dagger y Neal, 2006). La segunda centró su actividad en defender el derecho de la mujer a acceder a la educación elemental, pudiendo incluso incorporarse al ámbito universitario. Sarah Emily Davies fue además una sufragista activa, que reclamó para la mujer un papel determinante en un mundo andropolítico británico, promoviendo la «acción» como la forma de hacer conocer sus ideas. Para ellos fundó un grupo de discusión denominado Kensington Society, junto a la primera universidad para mujeres de Gran Bretaña, la llamada Girton College, que dirigió durante varios años. También destacó por la edición de varias publicaciones centradas en la temática feminista, de los que tuvo mayor relevancia su libro titulado The Englishwoman's Journal (Uglow, 1999).

Estos cambios tuvieron una repercusión considerable en todos los ámbitos. Las profesiones y los individuos que las ejercían tuvieron que adaptarse a nuevas necesidades de una población cambiante como lo fue la inglesa del siglo XIX. En el campo de la Enfermería, éste es el momento en el que se produce una modificación considerable en las competencias de las enfermeras. Entre otras cosas, se redistribuyeron las tareas y se procuró dotarlas de conocimientos teórico-prácticos reglados que perseguían un aumento en la calidad asistencial. Esta última había llegado a unos niveles muy precarios como consecuencia del empleo de mujeres que no sabían leer ni escribir y que no tenían ningún tipo de preparación académica para la administración de unos cuidados básicos adecuados (Castro Molina y Rodríguez Gómez, 2012). 
En este caldo de cultivo fue donde se generaron nuevos planteamientos que buscaban paliar esta nefasta situación. Florence Nightingale, quien trabajó en el Instituto de Diaconisas de Kaiserswerth en Alemania y en la Maison de la Providence de las Hermanas de la Caridad de París, se nutrió de una nueva concepción de la forma de cuidar. La formación adquirida le permitió llevar a cabo un plan de acción no visto hasta la fecha. En octubre de 1854 tuvo la posibilidad de poner en práctica sus ideas durante la gestión del Hospital de Scutari, lugar que prestaba asistencia a los heridos de la Guerra de Crimea (García Martín-Caro y Martínez Martín, 2007). Tras su regreso a Inglaterra, aquejada de una grave enfermedad, destacó, entre otras cosas, por su formación en matemáticas y estadística, situación que demostró al hacer públicos los resultados de las actuaciones acometidas en Turquía, llegando incluso a publicarlo en un libro que abordaba, entre otros temas, la calidad y administración hospitalaria militar. A él se le unieron sus conocidas Notas sobre hospitales en 1858, y Notas de enfermería en 1859, este último traducido a numerosos idiomas. En este mismo año, publicó Sugerencias para pensar para los buscadores de las verdades religiosas, en el que argumentaba una postura a favor de los derechos de las mujeres. Estos planteamientos influyeron en John Stuart Mill, autor del libro publicado en 1869 sobre los derechos de las mujeres, The Subjection of Women (Castro Molina, 2013).

En 1856, gracias a sus legendarias hazañas en Crimea, recibió el apoyo de la Reina Victoria y el Príncipe Alberto para su campaña para mejorar los Hospitales Militares, otorgándole además la Royal Red Cross y la Orden del Mérito. Incluso llegó a ser la primera mujer admitida en la Real Sociedad Estadística Británica y miembro honorario de la Asociación Esta-

\section{Imagen 2}

\section{NOTES ON NURSING :}

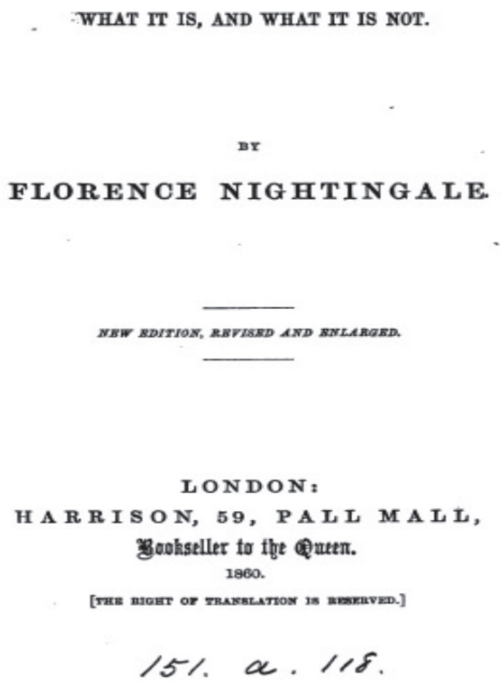

Notes on nursing, what is it, and what is not it (Florence Nightingale, 1860)

dística Americana. De John Delane, editor de The Times, y de otros amigos, obtuvo $£ 59,000$ para un proyecto en el que se había marcado como objetivo la fundación de una EscuelaCasa para enfermeras ubicado en el Hospital St. Thomas. En ésta, pretendía instruir a los profesionales de los cuidados según su doctrina, que resultaba ser una serie de pautas que ayudaban a desarrollar los cuidados de enfermería en los domicilios de desafortunados y desamparados (Castro Molina, 2012).

Su postura, próxima al feminismo, queda impresa en las diferentes publicaciones que nos han llegado producto de su pluma. Presentan una intencionalidad de crear un mundo dentro de la sociedad británica de uso exclusivo para la mujer, contrapuesto a la férrea hege- 
monía del hombre. Cuando aborda el campo de la enfermería emplea el género femenino, agregándole el rol a la mujer. Los médicos son denominados como «los hombres» para los que establece una tarea y profesión claramente definida. La exaltación de los valores femeninos es su herramienta con la que define su contracultura de lo mujeril, donde la enfermera está obligada a dar uso a la obediencia y sumisión a su práctica profesional.

Nightingale plantea el nacimiento de la figura de la enfermera, desarrollada por féminas con igualdad de derechos que los hombres, aunque profesionalmente con roles diferentes. Se apoya en la tradicional figura de la mujer como cuidadora, asociando el cuidado a la naturaleza femenina, lo que Sherry Ortner define como «la mayor proximidad de la mujer a la naturaleza por la capacidad biológica de engendrar, así como por la presencia de la mente femenina» (Ortner, 1981). A ello se le une el papel a desarrollar en el entorno en el que está inmersa. Para ella, el reconocimiento de autoridad es fundamental, no solo entre hombremujer, sino entre mujer-mujer. Esta última la considera fundamental para el ejercicio de la docencia y el control de las actividades de las enfermeras, el cual debe ser ejercido por una mujer. Esta autoridad es ajena a la supremacía tradicional, donde sus intereses deben buscarse en otro campo diferente al patriarcal. Pese a ello, refuerza la dicotomía hombre-mujer/ médico-enfermera otorgándole cualidades al hombre-médico que se contraponen a los atributos de una buena mujer-enfermera.

Tiene claro que el papel del médico y de la enfermera son diferentes: el rol de médico se le atribuye al hombre, mientras el de la enfermera lo asigna a la mujer. Mientras está a favor de la formación de las cuidadoras, no apoya el aprendizaje de la mujer en los cono- cimientos de la disciplina médica, además de ver inviable la incorporación del hombre a las actividades propias de los cuidados profesionales (Nightingale, 2002). Es decir, la igualdad es «con» y no «al» hombre médico, logrando así un refuerzo de la identidad femenina de la mujer-enfermera. Nightingale establece un discurso panegírico por la igualdad con el hombre, enfatizando en la importancia que tiene la formación en la mujer. Establece que es la necesidad la que estipula las actividades a desarrollar aunque puedan ser ajenas al rol de género, guiadas en todo momento por un ideario claramente definido que sirva de referente en la lucha por lo que considera justo, abogando así por la eliminación de todas las restricciones que bloqueaban a la mujer la posibilidad de adquirir estudios universitarios (Nightingale, 1859).

\section{BIBLIOGRAFÍA}

- Amorós, C. (2008). Mujeres e Imaginarios de la Globalización: Reflexiones para una Agenda Teórica Global Del Feminismo. Madrid: Homo Sapiens.

- Castro-Molina, F.J. (2012). Arquitectura y Medicina en Canarias. Dispositivos asistenciales y recursos sanitarios en Tenerife (s. XVI-XX) (Tesis doctoral). San Cristóbal de La Laguna: Universidad de La Laguna.

- Castro Molina, F.J. (2013). Nosocomios higienistas: el caso Florence Nightingale. Cultura de los Cuidados (Edición digital) 17 (36), 90-105. doi: 10.7184/ cuid.2013.36.11

- Castro-Molina, F. J., y Rodríguez-Gómez, J. A. (2012). Uniforme e imagen social de los cuidadores profesionales. Santa Cruz de Tenerife: Ediciones del Colegio Oficial de Enfermeros de Santa Cruz de Tenerife.

- Cott, N. (1987). The grounding of modern feminism. New Haven, Conn.:Yale University Press.

- Dagger, J., y Neal, D. (2006). Sex, Gender, and Religion: Josephine Butler Revisited. New York: Peter Lang Publihing, American University Studies, AUS. 


\section{Cultura de las Cuidados}

- García-Martín-Caro, C., y Martínez-Martín, M. L. (2007). Historia de la enfermería: evolución histórica del cuidado enfermero. Madrid: Editorial Elsevier.

- Howsbawm, E. (2009). En torno a los orígenes de la revolución industrial. Madrid: Editorial Siglo XXI.

- Jones, G.S. (1989). Lenguaje de clases. Estudio sobre la clase obrera inglesa. Madrid: Siglo XXI de España Ediciones S.A.

- Mill, J. S. (2005). El sometimiento de la mujer. Madrid: Editorial Edaf.

- Nightingale, F. (2002). Notas de enfermería. Barcelona: Masson.

- Nightingale, F. (1859). Sugerencias para pensar para legis- ladores de las verdades religiosas. London: s.e.

- Ortner, S. (1981). Sexual Meanings: The Cultural Construction of Gender and Sexuality. Massachusetts: Cambridge University Press.

- Salas-Iglesias, P. M. (2012). El reformismo social y sanitario de Concepción Arenal. Una contribución a la identidad de la enfermería contemporánea. Alicante: Editorial Club Universitario.

- Uglow, J. S. (1999). Northeastern Dictionary of Women's Biography. 3a edición. London: Macmillan Publihing.

- Wollstonecraft, M. (2012). Vindicación de los Derechos de la Mujer. Madrid: Ediciones Taurus, Great Ideas, número 10 .

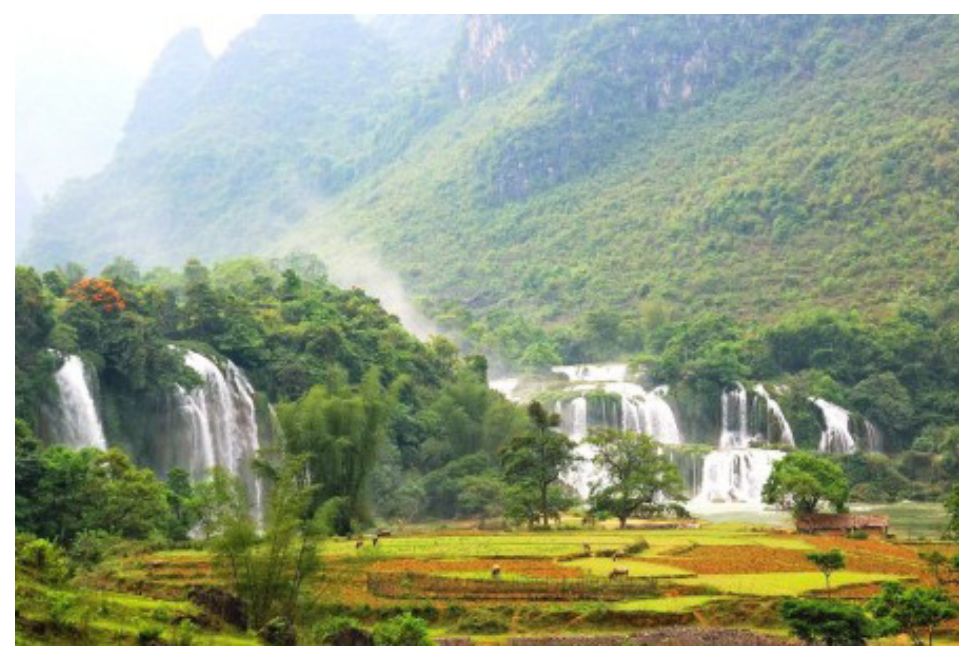

